\title{
Six Sigma and CMMI
}

\author{
${ }^{1}$ Neema Merlin Rodrigues, ${ }^{2}$ Anasuya K Lingappa \\ ${ }^{I}$ MTech Engineering Management, MIT, Manipal, \\ ${ }^{2}$ Assistant Professor, Dept. of Humanities \& Management, MIT, Manipal
}

\begin{abstract}
Quality is essential in every walks of life and in all business for their success and profitability. There are many quality improvement initiatives and they are doing their part well. The startups and initial organizations have to decide on which quality model to choose for their improvement and sustainability. CMMI has proved itself good in providing a proper infrastructure for the organizations. But it can be implemented in long term and is not useful in short term projects. Six Sigma can be applied in any field and has a statistical background. Integrating these two according to the need of the organization would give fast and sustainable success.
\end{abstract}

Keywords: Capability Maturity Model Integrated (CMMI), Six Sigma

\section{Introduction}

A mission success requires multiple approaches. There are too many competing initiatives for software quality improvement. All improvement initiatives should be implemented in an integrated fashion, not as layered or stove piped efforts and the results should be set of organizational processes used by everyone.

There is a Chinese proverb 'if you don't know where you are going any road will do'. So if we want to achieve success, we should have a specified path. Or else, any road will do. Watts Humphrey says that 'if you don't know where you are, a map won't help'. So after finding the path to follow to succeed from the map, we should know exactly where we are currently. Otherwise there is no use of map. This makes it clear that the company should know its current situation and then find the right path to follow to be successful in the market in long run.

Six Sigma is structured, statistical and proved successful in manufacturing industry. It was used in manufacturing in the first wave, in service/transactional industry in the second wave and now in the third wave in engineering/software industry. The Six Sigma philosophy is to improve customer satisfaction through the prevention and elimination of defects and as a result, increase business profitability. Six Sigma defines defects in terms of the customer's (not the engineer's) viewpoint. Six Sigma techniques provide metrics to make timely fact based management decisions. Typical software processes operate between 2.3 and 3.0 sigma and the best software processes operate at 4 and 5 sigma.[11] Our target should be 6 sigma.

CMMI was developed by the SEI, part of Carnegie Mellon University in Pittsburgh, Pennsylvania, USA (a non-profit group sponsored by DoD). CMMI as a process improvement methodology has four process areas which are process management, project management, engineering and support.[8]

\section{Comparison of Six Sigma and CMMI}

CMMI identifies what activities are expected in the processes while Six Sigma identifies how they can be improved. Six Sigma identifies what activities are needed in the organization while CMMI identifies how they can be implemented. CMMI helps Six Sigma in setting up organizational infrastructure. Six Sigma connects process improvement and business value by identifying customer needs and reducing defects. CMMI focuses on organizational change. Six sigma focuses on performance of processes and practices rather than checking compliance against a definition or model as in CMMI. Both are complementary forces. CMMI is a legacy method for long term projects using waterfall model which is more complicated and gives accurate output. CMMI is an interconnected and hence stable model, with more detailed coverage of the product life cycle than other process improvement alternative products.[9] CMMI audit uses checklists. It has no statistical support as for Six Sigma.[11]

\section{Integration of Six Sigma and CMMI}

Six Sigma can be effectively used in all maturity levels of CMMI. In general, six sigma can be an enabler for implementation of improvement models like CMMI. The objective of the six sigma project team is to implement, improve or optimize a process area or a group of process areas, in this case. Depending on the situation, frameworks like DMAIC, DFSS and lean can be used. Map the model to the process, not the process to the model. 
Another method is the continuous improvement of the organization by Six Sigma using CMMI infrastructure. They reinforce each other. Six Sigma is considered to be equivalent to the level 4 and 5 of the CMMI maturity levels. To reach the six sigma level in less time, six sigma process should be applied from the lower maturity levels.

Table I : Six Sigma phases associated with key process areas of CMMI maturity levels

\begin{tabular}{|c|c|c|c|}
\hline CMMI Level & Focus & Process Areas & Six Sigma Phase \\
\hline \multirow[t]{2}{*}{5 Optimizing } & \multirow[t]{2}{*}{$\begin{array}{l}\text { Continuous Process } \\
\text { Improvement }\end{array}$} & $\begin{array}{l}\text { Organizational Innovation \& } \\
\text { Deployment }\end{array}$ & Improve \\
\hline & & Causal Analysis \& Resolution & Analyze \\
\hline \multirow[t]{2}{*}{$\begin{array}{l}4 \text { Quantitatively } \\
\text { Managed }\end{array}$} & \multirow[t]{2}{*}{ Quantitatively Managed } & $\begin{array}{l}\text { Organizational Process } \\
\text { Performance }\end{array}$ & Analyze \\
\hline & & $\begin{array}{l}\text { Quantitative Project } \\
\text { Management }\end{array}$ & Control \\
\hline \multirow[t]{14}{*}{3 Defined } & \multirow[t]{14}{*}{ Process Standardization } & Requirements Development & Define \\
\hline & & Technical Solution & Improve \\
\hline & & Product Integration & Improve \\
\hline & & Verification & Measure \\
\hline & & Validation & Measure \\
\hline & & Organizational Process Focus & Improve \\
\hline & & $\begin{array}{l}\text { Organizational Process } \\
\text { Definition }\end{array}$ & Define \\
\hline & & Organizational Training & Improve \\
\hline & & $\begin{array}{l}\text { Integrated Project Management } \\
\text { (with IPPD extras) }\end{array}$ & Control \\
\hline & & Risk Management & Control \\
\hline & & Decision Analysis \& Resolution & Analyze \\
\hline & & Integrated Teaming(IPPD only) & Define \\
\hline & & $\begin{array}{l}\text { Organizational Environment for } \\
\text { Integration (IPPD only) }\end{array}$ & Control \\
\hline & & $\begin{array}{l}\text { Integrated Supplier } \\
\text { Management(SS only) }\end{array}$ & Improve \\
\hline \multirow[t]{7}{*}{2 Managed } & \multirow[t]{7}{*}{ Basic Project Management } & Requirements Management & Analyze \\
\hline & & Project Planning & Define \\
\hline & & Project Monitoring \& Control & Control \\
\hline & & $\begin{array}{l}\text { Supplier Agreement } \\
\text { Management }\end{array}$ & Define \\
\hline & & Measurement \& Analysis & Measure \\
\hline & & $\begin{array}{l}\text { Process \& Product Quality } \\
\text { Assurance }\end{array}$ & Improve \\
\hline & & Configuration Management & Define \\
\hline 1 Initial & Informal \& Ad hoc Process & & \\
\hline
\end{tabular}

Six Sigma provides mechanism to sustain in the improved stage. It accelerates the transition of CMMI. Basic training on the methodologies used should be given to all employees and selected people should be trained well to guide others. Standard six sigma training does not directly relate to software development. Shared roles in both methodologies and cross training are essential.

Most of the six sigma projects for software improvement is performed in an ad hoc way.[3] Software six sigma projects should concern all aspects of SDLC. Six Sigma is an effectively integrated approach. Six sigma is structured, statistical and is found successful in manufacturing industry. So it can be applied in software industry too.

New methodology can be developed combining CMMI and six sigma. The business methods linked with software can be patented. Six sigma is in level 4 or 5 of CMMI for continuous improvement and technology changes. But it should be started from the very beginning - lower levels of maturity to accelerate the transition between maturity levels.[10]

\section{Literature Review}

The waves and megatrends of the software industry are (1st wave) waterfall lifecycle and structured models, (2nd wave) Process Maturity Movement and (3rd wave) Software industrialization.

Quality is defined as "the essential character of something, an inherent or distinguishing character, degree or grade of excellence" in Webster's dictionary. A Quality Model is a model with the objective to describe, assess and/or predict quality. Quality Model can be provided in different forms ex: international standards, checklists or implicitly by certain tools.[1] ISO defines "software quality" as the totality of characteristics of an entity that bear on its ability to satisfy stated and implied needs (Dale,1999).[2] 
Quality models play a central role in quality analysis projects. They are used to be able to make a quality statement. They are aggregation of quality evaluations and measurements, communication with customers, benchmarking software and tools and decision making support. One thing is worse than not having your product out there early, having a detective product and early.

Organizations need to focus on improvement if they wish to build a competitive advantage, rather than perceiving quality management solely in marketing terms.[2] The assurance of software quality affects both immediate profitable and long-term retention of customer goodwill. Gary Hamel, most renowned strategy thinker says it is time to usher in new management principle and all new principles should be based on high order innovation and achieves true engagement with human talent in the company. Numatic international follows the fact that the essence of the company's success is to be able to give customers the exact specification they want in a very short space of time.[6]

CMMI integrate the best part of process development, product development, Software Engineering, supplier sourcing \& Systems Engineering into a single model. It is the most common model for assessing the process maturity of a product development organization in the US. It does not discuss about personnel management, but strictly discusses development processes. Also discusses Project Management broadly and specifically.

CMMI requires the establishment of a configuration management system that fulfills several requirements. It requires that design interfaces be established and that alternatives be evaluated when making decisions. It provides no guidance regarding the writing of code. CMMI recommends verification, although it provides little specific guidance on how to perform them. It also requires that virtually everything be documented and recorded, but no guidance is given on how to construct good document.

The strategies for integrating the CMMI and Six Sigma are :

1. Implement CMMI based processes (CMMI process areas) as Six sigma projects.

2. Apply Six sigma to improve process performance and serve at the tactical engine to achieve highly capability and /or maturity.

3. Apply Six sigma specifically DFSS as a tactical contributor to achieve highly capable engineering processes.

4. Apply Six Sigma to improve or optimize as organization's improvement strategy and processes.

5. Institutionalize Six Sigma project results and culture via the CMMI's institutionalization practices.

6. Develop an internal process standard that maps to or integrates the CMMI ,Six sigma and all other improvement initiatives of choice. This standard defines the process by which every project is to be executed across its entire lifecycle.

\section{Research Methodology}

The software field is emerging now a days. The quality of software product, service and the company as a whole matters in the tight competition between the companies. It is very hard for the new or emerging small companies to withstand in the market. We should look at the broader aspect of quality. Expicient is a supply chain software products and services firm. They produce their own software suites or tools. But they are mainly into configuration and maintenance of IBM/Sterling and Manheader software. My study is only based on the quality management department of Expicient Inc., Bangalore.

An explorative research study was done in the software development and maintenance area. Exploratory research is done to discover ideas and insights and to have a better understanding of the situation. It is not designed to come up with final answers or decisions. So it should not be expected to provide answers to the decision problem you are attempting to solve. Rather it can provide very rich, meaningful information or even definitive explanations for particular individuals. It does not provide definitive answers for the overall population because (1) it involves only a relatively small group of people and (2) these people are almost never randomly selected to participate. This study help define the problem, increase a researcher's familiarity with a problem. The method is relatively small in size.

The types of exploratory research used in my work are literature study, depth interviews and case analysis. Focus group method was not used. Benchmarking was done while fine-tuning the CMMI audit template.

The work in the company was done in two phases. The first part was study of CMMI method and the second Agile Scrum method. After doing an exploratory study of the company and its methods, CMMI audit was done for one project. The agile method was studied and was presented. Six Sigma methodology was also studied which can be incorporated in the firm for better results.

To do CMMI audit, the CMMI methodology was studied in detail. The audit template was fine tuned according to the company profile. Using this template, audit was done. The suggestions and corrective actions against non-conformances were given. The corrections were done and were inspected. The suggestions given to 
the company were considered. Some of the suggestions were accepted and implemented. Assessment cycle continues until one reaches level 5 .

Another method used was interviews with the Managers. Shunyyu Suzuki says that "in the beginner's mind there are many possibilities, but in the expert's mind there are few". So interaction with the Senior Manager and the Quality Manager helped in understanding the situation better and faster. They gave review for my work and guided me.

Software Process Assessment is an appraisal or review of an organization's software process. An audit is a primary mechanism for assessment and is an independent examination of a work product or set of work products to assess compliance with specifications, standards, contractual agreements or other criteria.

Quality Management of software includes Knowledge Management, Defect Management, Configuration Management, Risk Management and Project Management. So all these fields are considered in my work, but not in detail because of the time limit.

\section{Results And Discussion}

Functional requirements gathering was absent in the organization. This led to confusion during the project design and implementation which result in defects or wastage. Once it was noted, suggestion was given to gather functional requirements from the client in the requirements gathering phase. The suggestion was accepted by the team. This helped in satisfying the customer and making more efficient products and services.

The company has defined software development model of its own which is called Expicient Software Development Process (ESDP). But it was not followed in all projects. Depending on the requirements of the clients, the tools used changes and this shows that the company is still in the level 2 (managed or repeatable) to level 3 (defined) stage of CMMI. The interview with the QM Manager and the Senior Manager confirms this.

Timeliness and cost are the only quality parameters focused on. So testing was not done properly to meet the timeline. Other parameters such as functionality, Engineering, adaptability, performance and understandability can be considered. Proper unit testing in the development phase and functional, integration, user acceptance and performance testing in validation phase should be ensured for that.

Relationship matrices and questionnaires are the tools used by the quality management department. There is no universally accepted matrices for software quality measurement i.e. assurance or control. So standard tools can be used for measurement. Statistical methods like six sigma would be better because it has a solid base rather than assumptions or beliefs.

There are no quality policies, standards or certifications in the company till now. The waterfall model is used only for big projects with already stated requirements. Most of the projects follow agile methodology. Quality models related to that can be used and policies and standards accepted. This will help in getting quality certifications which help in attracting and delighting customers.

The organizational design in the company is vertical. The modern companies following agile or spiral methodologies prefer horizontal design.

Training programs are essential for employees to be in a quality culture.[7] Now there is no internal training in the company. But external training is promoted. If there is compulsory internal or external training employees will gradually come to quality culture. For training and to follow quality methods they should also be motivated. The only key to improve quality realistically is motivation from within an organization. [4] To motivate, recognitions and rewards can be given for best works. Here comes the concept of learning organization and the organization should learn together continuously to succeed.[5] Deming says learning in quality signifies the reduction of variation. The company should be driven by knowledge.[5]

The use of a common Project Management software for the company will help in efficient and effective management of software life cycle processes. I suggested the use of MS Project 2013 which has good features including cloud support. Each individual has separate login and access permissions. The company was using MS Excel for Project Management. The use of MS Project will give better results.

As mentioned in the research methodology, the Quality Management includes many fields. So there should be someone to help the Project Manager. After the suggestion was given, a Prime was appointed with each PM.

The design of the project is made after analyzing the requirements and their feasibility. It should be reviewed to avoid problems later. This was not done before and due to that time and resources were found to be wasted. Now design is reviewed before proceeding to the next phase. Also issue tracker software is used to track and solve the issues as it happens, which was not done before.

All the above points can be key areas to be considered in six sigma projects. Thus the performance of the company can be improved to make long term profit. 


\section{Conclusion}

Organizations can integrate CMMI, six sigma and other improvement initiatives according to the need of specific organizations by making their own standard processes. Their joint initiatives are synergistic. Organizations may have inertia of changing from the existing situation. But once it overcomes this difficulty it will be good for the individuals as well as the entire organization and business. It should grow as a culture in the organization and the entire software industry. Certification only benchmarked the starting of QM and is not the end of a quality assurance scheme of a company.[4] Quality is a way of life.

Just getting started is half the battle. So if we start implementing the combination of CMMI and Six Sigma it will go on well with a little effort. If we do not know what to do, Picasso's words should be our motivation - "I am only doing what I can't do, so that I may learn to do it".

\section{Limitations And Future Scope}

While the goal of Six Sigma is to produce defect free product, it is not the solution for every business situation. If the cost outweighs the benefit, Six Sigma is not advisable.[10]

The company is in its transition from level 2 to level 3 of CMMI. The future work can be to check whether the company reached level 3 and then to the next levels. These can be six sigma projects.

Six Sigma works well with light weight incremental or evolutionary software development life cycles. Waterfall model does not support a philosophy of rapid continuous improvement. So Six Sigma can be better integrated with other methodologies like agile for better results. CMMI level 5 companies cut cost in half with Agile Scrum.

\section{References}

[1] Stefan Wagner, Klaus Lochmann, Sebastian Vinter, Andrew Goeb, Michael Klaes, "Quality Models in Practice : A Preliminary Analysis"

[2] Rodney McAdam, Frances Fulton, "The impact of the ISO 9000:2000 quality standards in small software firms", Emerald Insight, 2002

[3] Zhedan Pan, et al., "A six sigma framework for software process improvements and its implementation", 14th Asia-Pacific Software Engineering Conference

[4] Tommy Y Lo, "Quality culture : A product of motivation within organization", Emerald - Managerial Auditing Journal, 2002

[5] Dr. Santwana Chaudhuri, "Knowledge Management in Indian IT Industries", 3rd international conference on information and financial engineering, 2011

[6] Alastair Ross, David Francis, "Lean is not enough", IEE Manufacturing Engineer, Aug/Sep 2003

[7] K Subrahmanya Bhat, Jagadeesh Rajashekhar, "An empirical study of barriers to TQM implementation in Indian industries", The TQM Magazine, Vol 21, No 3, pp 261-272, 2009

[8] Uuno Puus, Tonis Mets, "Software Development maturity evaluation : six cases from Estonian SMEs", Baltic Journal of Management, Vol 5, No 3, pp 422-443, 2010

[9] Rodu Constantinuces, Ioan Mihnea Iacob, "Capability Maturity Model Integration", Journal of applied quantitative methods, Vol 2, No 1, Spring 2007

[10] G Y Hong, T N Goh, "Six Sigma in software quality", The TQM Magazine, Vol 15, No 6, pp 364-373, 2003

[11] Rupa Mahanti, Jiju Antony, "Confluence of Six Sigma, Simulation and Software development", Managerial Auditing Journal, Vol 20, No 7, pp 739-762, 2005 